BRÈVย

Partenariat médecine/sciences Association Médecine/ Pharmacie-Sciences (AMPS)

\section{Répartition des tâches chez les cellules dendritiques plasmacytoïdes humaines}

> Les cellules dendritiques plasmacytoïdes sont un sous-type de cellules immunitaires particulièrement importantes pour la réponse aux infections virales via leur sécrétion abondante d'interféron (IFN) de type I. Elles existent à l'état inactif dans les tissus et les organes lymphoïdes, et sont activées par la reconnaissance d'acides nucléiques - viraux dans le cas d'une infection, mais aussi humains dans certaines maladies auto-immunes comme le lupus [1]. Jusqu'à récemment, les cellules dendritiques plasmacytoïdes étaient considérées comme une population se transformant de façon univoque en cellules effectrices assurant, d'une part, une première défense antivirale par leur sécrétion de grandes quantités d'IFN $\alpha$ et $\beta$, et, d'autre part, la mise en place de l'immunité

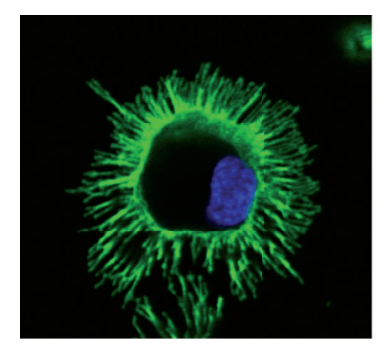

(c) Sophie Viaud, U1015 Inserm
P3. La réalité de ces trois populations distinctes au sein des cellules dendritiques plasmacytoïdes est attestée par une signature transcriptionnelle spécifique à chaque population, ainsi que par la stabilité du phénotype dans le temps. La cytokine TNF $\alpha$ (tumor necrosis factor $\alpha$ ) alpha semble jouer un rôle dans ce processus de différenciation, mais il reste à comprendre les mécanismes précis de communication cellulaire conduisant à la ségrégation d'un compartiment de cellules dendritiques plasmacytoïdes identiques en trois populations distinctes phénotypiquement, morphologiquement et fonctionnellement, en réponse à une stimulation. Le démembrement de cette population pourrait avoir un impact thérapeutique. En effet, si différents sous-types se partagent les fonctions essentielles des cellules dendritiques plasmacytoïdes, on peut imaginer cibler spécifiquement ceux qui seraient adaptative en migrant du lieu de l'infection jusqu'aux ganglions pour $y$ activer les lymphocytes spécifiques du virus causant l'infection. Cependant, l'équipe de Vassili Soumelis (Institut Curie, Paris) vient de montrer que, loin d'être une population homogène, les cellules dendritiques plasmacytoïdes se répartissaient en trois sous-populations divergeant phénotypiquement, fonctionnellement et morphologiquement en réponse à un stimulus unique [2]. En particulier, l'expression des marqueurs membranaires PD-Ll (programmed death-ligand 1 ) et $\mathrm{CD}^{1} 0^{1}$ constitue un marqueur discriminant. Une première population ( $\mathrm{Pl}$ ) exprime fortement PD-Ll et faiblement CD80 ; elle sécrète les IFN $\alpha$ et $\beta$ au niveau du site de l'infection. Cette sous-population, dont la capacité migratoire est limitée, semble rester au niveau du site initial d'infection et la combattre avec l'aide des acteurs de l'immunité innée. De plus, la proportion de cellules $\mathrm{Pl}$ parmi les cellules dendritiques est enrichie chez certains patients souffrant de maladies caractérisées par une forte concentration d'IFN de type I, comme le lupus ou le psoriasis. La population P3, qui, à l'inverse, exprime fortement CD80 et faiblement PD-Ll, aurait pour fonction de faire le lien entre l'immunité innée et l'immunité adaptative. $\varepsilon$ n effet, les cellules P3 ont une morphologie plus allongée coïncidant avec leur grande capacité migratoire, et, in vitro, activent les lymphocytes. In vivo, elles seraient responsables de l'activation de cellules de l'immunité adaptative au niveau des ganglions lymphatiques. Une troisième population, P2, exprime les deux marqueurs et partage les caractéristiques de $\mathrm{Pl}$ et de

${ }^{1}$ CD80 (ou B7.1) est une molécule de costimulation des lymphocytes T. dérégulés sans affecter les autres sous-populations fonctionnelles. $\nabla$

\section{RÉFÉRENCES}

1. Swiecki M, Colonna M. Nat Rev Immunol 2016; 15 : 471-85 2. Alculumbre SG, et al. Nat Immunol $2018 ; 19: 63-75$.

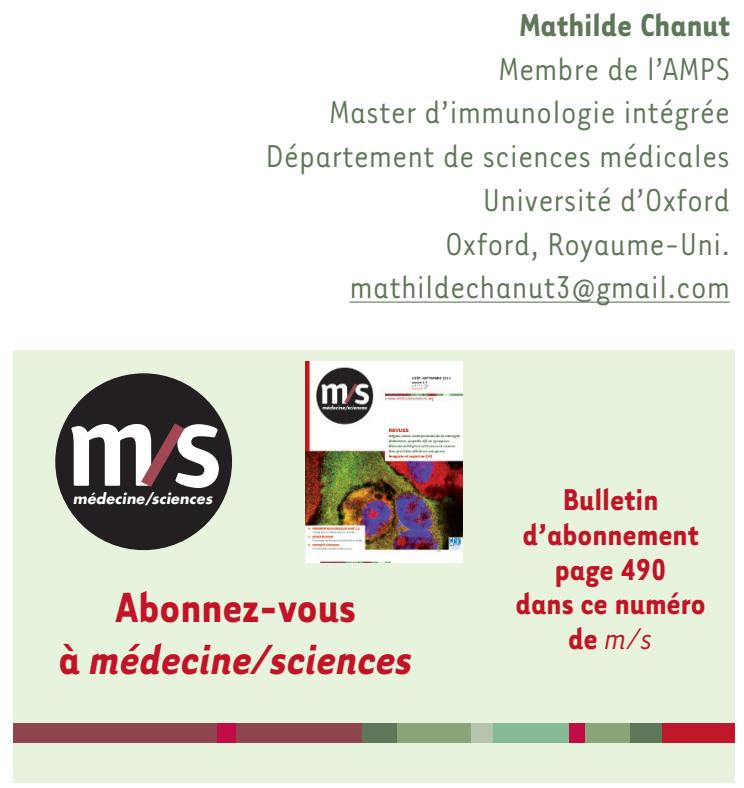

Mathilde Chanut Membre de l'AMPS Master d'immunologie intégrée Université d'0xford Oxford, Royaume-Uni.

(1)

